Document downloaded from:

http://hdl.handle.net/10251/98023

This paper must be cited as:

Jiménez Bello, MA.; Martínez Alzamora, F.; Bou Soler, V.; Bartolín Ayala, HJ. (2010). Analysis, assessment, and improvement of fertilizer distribution in pressure irrigation systems. Irrigation Science. 29(1):45-53. doi:10.1007/s00271-010-0215-7

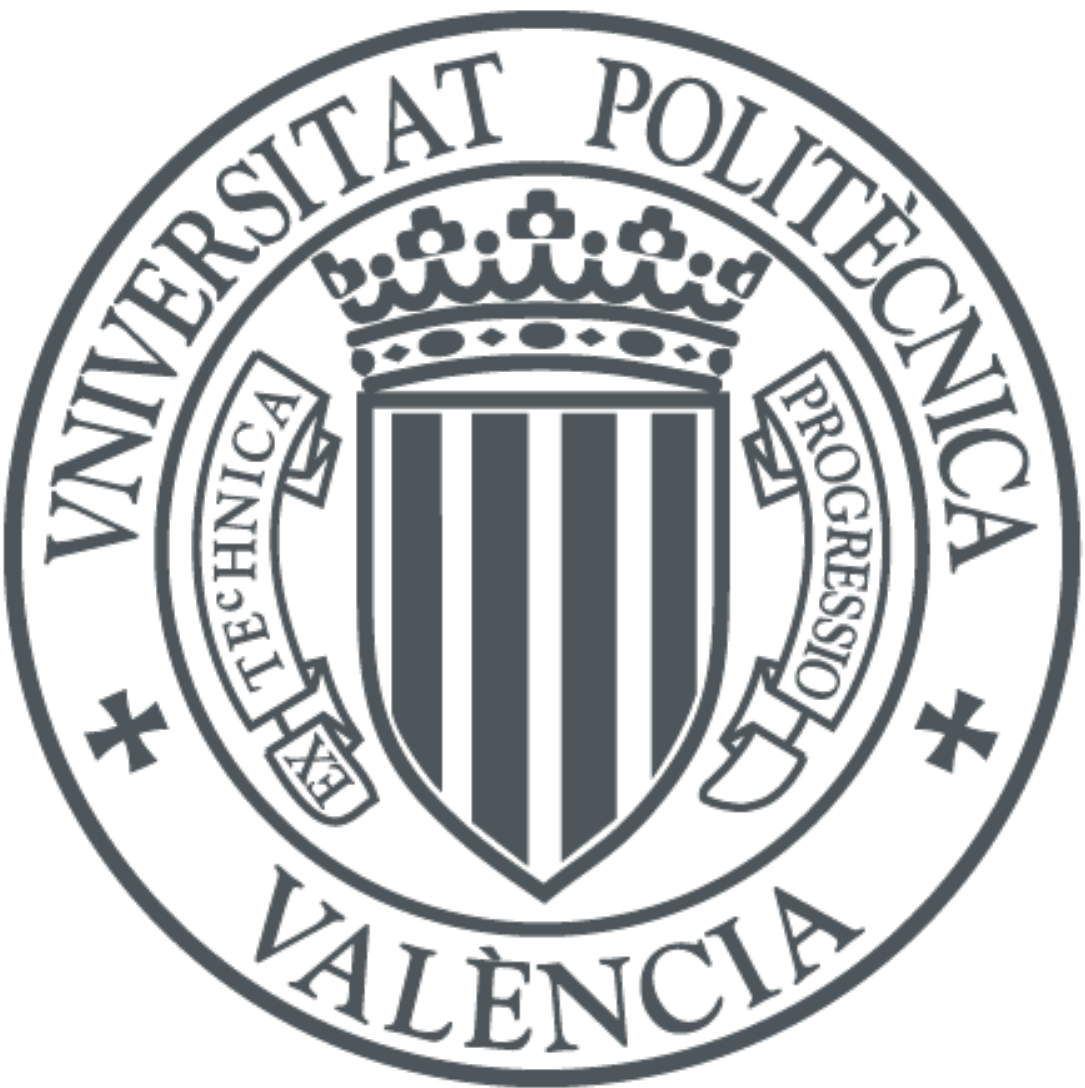

The final publication is available at

http://doi.org/10.1007/s00271-010-0215-7

Copyright Springer-Verlag

Additional Information 


\title{
Analysis, assessment and improvement of fertilizer distribution in pressure irrigation systems
}

\author{
Miguel Angel Jimenez-Bello •Fernando Martínez •Vicente Bou •Hugo Bartolín \\ Instituto de Ingeniería del Agua y del Medio Ambiente, \\ Universidad Politécnica de Valencia, Valencia, Spain \\ e-mail: mijibar@dihma.upv.es
}

\begin{abstract}
The transformation of traditional irrigation systems into pressure irrigation networks allows water users associations to use central fertigation systems. For efficient fertigation management, however, it is essential to obtain uniform distribution of the injected fertilizer through the system and to understand the hydraulic processes that take place in the central fertigation system. This will allow users to implement strategies that improve fertilizer distribution. In this work we develop a new methodology to improve fertilizer distribution uniformity and apply it to a case study. The results show how fertilizer distribution can be improved by means of proper scheduling of irrigation deliveries. The best results are obtained when fertigating sectors operate without nonfertigating sectors and there are not intermediate irrigations without fertilizer, achieving an improvement of the fertilizer distribution of $10.5 \%$. In addition, this work highlights the difficulties of obtaining uniform distribution of fertilizer in a centralised irrigation system when there are users that do not want to make use of it.
\end{abstract}

Keywords:, Fertigation, irrigation networks, sectoring, Genetic algorithms, EPANET

\section{Introduction}

Pressurised distribution networks allow the efficient use of the available water resources through the exhaustive control of water inputs to meet demand. In particular, drip irrigation allows the application of fertilizers into the water (fertigation) in such a way that both water and nutrient requirements are met using the same distribution system. While fertigation is common practice in on-farm irrigation systems, the increasing number of collective pressure irrigation networks has allowed the use of collective filters and centralised fertigation systems. This practice, unthinkable not so long ago, has been adopted by many Water Users Associations (WUA) in Spain to irrigate monoculture crop areas of between 200-1000 ha(Arviza and Balbastre 2000a, Arviza and Balbastre 2000b).

Fertilizer distribution has been studied in drip irrigation systems at the sub-unit level, in terms of injector (Bracy et al 2003; Jiusheng et al 2007) and emitter type (Jiusheng et al 2007). However, fertilizer distribution 
management and the appropriate design requirements of the network have not been studied. Arviza et al (2002) highlighted the need to take into account the distribution of fertilizers in the network and the potential of water quality and hydraulic simulation tools such as EPANET (Rossman 2000).

In centraliesed fertigation systems, network sectoring is the only logical way to apply fertilizers efficiently. Knowing the operation times of the farm intakes is necessary to prepare suitable fertilizer concentrations and efficiently distribute the fertilizer through the system. For this reason on-demand irrigation is not recommended.

An irrigation sector can be defined as the set of water intakes that operate simultaneously. The operation time of the intakes is called an irrigation shift. Sectoring depends on the degree of automation of the network. A network system with automatic valves at each water intake monitored by a control unit allows the independent operation of the network sectors. On the other hand, a network system with valves installed only at the head of the system assumes the simultaneous operation of all downstream intakes.

Because the fertilizer needs a travel time to flow from the injection point to the demand points, the irrigation sectors must be organized in such a way that the fertilizer reaches the intakes in a uniform way. Fertilizer management becomes more complex when some users do not make use of central fertilization because they want to fertilize on their own, or because they practice organic farming. As a consequence, there may be phases in the network operation where there is no fertilizer in the system. Similarly, after this period of operation, the fertilizer has to travel again through the system after it is injected.

The operation of a WUA with centralised fertigation is analyzed in this work. The methodology for assessing the performance of the case study and proposals for a more efficient distribution of fertilizer are described. The factors affecting the efficient performance of the fertigation system in the WUA are also analyzed.

\section{Methodology}

\subsection{Case study}

The Water Users Association of Senyera is located in the municipality of the same name in the province of Valencia (Spain). It consists of 387 plots; a subplot belongs to the WUA if it is connected to an irrigation intake. The total area of the WUA is 116 ha, from which 77.5 ha are irrigated (283 plots). Average plot size is $3093 \mathrm{~m}^{2}$. The system has 52 multi-outlet hydrants and a total of 331 intakes, 224 of which were in operation in 2006. The network topology is of a branched type. Water supply is by gravity through an open channel that feeds an irrigation pond. This has an inlet and an outlet to ensure that the pond is always full without water overflow. Water control is carried out by two pumping units: one fixed speed pump and one variable speed pump monitored by a variable frequency drive (VFD). Pump power is $37 \mathrm{~kW}$. A central control system regulates intake opening with electro valves, assigning them a specific irrigation time or volume. The system allows the automatic reading of water consumption for each intake and specific irrigation period. 
The WUA is managed by a company in charge of the system control and maintenance. The technical staff consists of a technician responsible for system planning and control, and an operator whose task is to verify the correct operation of the facility during irrigation and maintenance and to supervise flow meter readings. The first day of each month the intake meters are read and the water consumption is billed to the users, charging an extra amount to users that fertigate. Irrigation of each sector is arranged into shifts and the intakes are distributed into six irrigation sectors (S1, S2, S3, S4, S5, S6). The strategy followed by the technical staff responsible for the sectoring of the system consisted of grouping the intakes into sectors of similar size. Each sector is irrigated during one scheduled shift.

The technician schedules in advance which days to irrigate and fertigate each sector. In the season under study, fertigation was performed two days per week with intermediate irrigation days without fertilizer. Each irrigation shift lasts two hours. The sectors are irrigated in sequence during the day. The last irrigation shift (S6) corresponds to the sector that is not fertigated. Irrigation begins at 6:00 am and ends at 6:00 pm. The fertilizer pump begins at 6:00 am and ends at 3:30 pm, 30 minutes before the irrigation shift without fertilizer (S6) begins to operate.

\subsection{Assessment of fertigation performance}

In order to assess how the fertilizer is distributed through the network, the WUA was modeled using the decision support system (DSS) HuraGIS (Jimenez et al 2006). This DSS is implemented in a geographic information system (ArcGIS 9.x). HuraGIS can store data required to simulate the agronomic and hydraulic processes involved in pressurized irrigation management systems. The hydraulic simulation was carried out using EPANET (Rossman 2000). This software performs extended period simulations of hydraulic behavior and water quality in pressurized networks. HuraGIS can generate time patterns, assign them an EPANET scenario and analyze the results with the EPANET toolkit.

The mathematical model of the network represents the network elements at the level of multi-outlet hydrants. The model was calibrated by means of pressure sensors placed at four hydrants and the network head. The water flow meters of each intake were used to measure the water flows. Since intake flows and pipe diameters were known, pipe roughness of each diameter size was chosen as the calibration variable. Due to the restricted number of pressure sensors, criterion used to choose hydrants was to maximize the number of equations that include the eight diameter sizes existing in the network. For this reason selected hydrants were located at the end of network branches. The total number of equations was six, one for each hydrant plus two extra equations because there were two hydrants having intakes operating in two different sectors. The goal function was to minimize the quadratic error of the estimated pressure versus the measured pressure. The relative pressure error in the model was $2.78 \%$.

The water quality module of EPANET was also tested. Fertilizer travel times were measured at several intakes under known working conditions. For that purpose, phosphoric acid was injected into the network through the fertilizer pump and an operator recorded the time at which $\mathrm{pH}$ variations were detected using $\mathrm{pH}$-indicator strips. The differences between the measured times and those generated by the model were less than one minute. This 
difference was considered negligible ( $<1 \%$ of the application period) when assessing the distribution of the fertilizer in the study case.

The sum of the intake flows of each hydrant was considered the base demand of each node modeled as a hydrant in EPANET. Time patterns, which represent the operation schedule of the intakes, were generated for each hydrant. Injection of fertilizer into the network was simulated using the option Source Quality of the node that represents the irrigation head. Since the injection device is a pump that injects a constant concentration of fertilizer, the option Flow Paced Booster was used. A pattern curve simulating the beginning and end of fertilizer injection was created and assigned to the irrigation head. The Quality Time and Hydraulic Time Step were set up (Rossman 2000) using the recommended intervals (Arviza et al 2002) of 5 seconds and 10 minutes, respectively.

Once the simulation for each intake was performed, the time required for the fertilizer to reach the intake was calculated $\left(T_{\text {Travel }}\right)$. Fertilization time $\left(T_{\text {Fert }}\right)$ was calculated as the time an intake was taking fertilizer. Finally the ratio between $T_{\text {Fert }}$ and the irrigation time scheduled for each intake $\left(T_{\text {Irri }}\right)$ was calculated and termed the Effective Fertigation Time $(E F T)$. The average EFT (EFT avg $)$ and standard deviation of EFT (EFT $\left.T_{S t d}\right)$ was calculated for each sector and all operating intakes of the network

\subsection{Improvement in the Effective Fertigation Time by Genetic Algorithms.}

To improve EFT, a genetic algorithm (GA) was created to study the network sectoring that maximized $E F T_{\text {avg }}$ or minimized $E F T_{S t d .}$ A GA is a heuristic method based on the mechanisms of evolution and natural selection (Goldberg 1989). GA is an efficient method to solve non-linear optimization problems and is widely used in water resource planning and management (Savic and Walters 1997).

The decision variables in the analysis were the network sectors that contain a water intake. Water intakes that belong to the same multi-outlet hydrant were grouped together into one sector as the water intakes belonging to one hydrant work simultaneously for maintenance and operation purposes. The number of sectors and the duration of each irrigation shift were as previously defined. In this case study, water control was performed by two pumping units and the minimum number of sectors fertigated was determined by pump power. For the case study, fewer than five sectors is not feasible because the pumps have insufficient power to supply water at the required hydrant pressure $(0.25 \mathrm{MPa})$

In a GA analysis, a chromosome represents a legal solution to the problem and is composed of a string of genes. A gen represents a possible value for a decision variable. The number of decision variables is determined by the number of water intakes or hydrants. Each gene takes an integer value corresponding to an irrigation sector that operates during an irrigation shift. Each chromosome will be evaluated as a solution to the optimization problem. An initial population of chromosomes is randomly created. Time patterns were generated for the hydrants and the hydraulic simulation was performed using EPANET (Rossman 2000). A fitness value was set up for each chromosome. This value was derived from the objective function, which either maximized 
$E F T_{\text {avg }}$ or minimized $E F T_{S t d}$. Where the pumps did not enough power to supply water at the minimum required pressure, the fitness value of the chromosome was penalized. The chromosomes with higher fitness values were selected to be crossed and generate offspring. The new generation was then evaluated until a number of generations certain condition was reached. When the last generation was calculated the chromosome with the best fitness value was selected as the final solution.

\subsection{Compatibility of the improvement in the Effective Fertigation Time with energy consumption}

Network sectoring was also studied in terms of energy consumption. In this work, a sectoring option was considered better than others if an irrigation day showed a lower energy consumption rate. For this purpose a methodology based on the optimization by GA of irrigation networks controlled by direct injection pumps was used (Jimenez et al 2008). The objective function was:

$$
\begin{aligned}
& W_{\text {PumpJ }}=\sum_{j=1}^{N_{\text {Shitt }}} \sum_{i=1}^{N_{\text {Pump }}} \frac{Q_{i, j} \cdot H_{i, j}}{\eta_{p, i, j} \cdot \eta_{\text {eng }, i, j}, \eta_{v f d, i, j}} \cdot T_{j} \\
& W_{\text {Pumps }}: \text { Energy consumption in an irrigation day }(k W h) \\
& T_{j} \text { : Duration of Shift j (h) } \\
& N_{\text {Shift: }} N \text { of Shifts } \\
& \eta_{p, i, j} \text { : Global efficiency of pump i at Shift } j \\
& N_{\text {Pump }}: N \text { of pumps } \\
& Q_{i, j}: \text { Flow of pump i at Shift } j(l / s) \\
& H_{i, j} \text { : Total head of pump i at Shift } j(m)
\end{aligned}
$$

Pump curves as supplied by the manufacturer were used as the pumps were installed in the season of study. Engine and variable frequency drive curves provided by the manufacturer were also used. The relative error of estimated energy consumption versus measured energy consumption for an irrigation day was $0.5 \%$.

\subsection{Sector sequence}

EFT effects on crop yields, fertilizer savings and reduction of pollution by leaching were not studied. Multiobjective techniques can be used to assess management strategies (Kalyanmoy 2001). In this sense, the optimal sectoring of the network in terms of energy consumption were analyzed so as to find out the best sector sequence, i.e. the order of sectors along an irrigation day that improved EFT. Once the network sectors had been defined, all possible combinations were set up. The number of possible combinations was 


$$
N_{\text {PosComb }}=\left(N_{\text {Sector }}-1\right) \text { ! }
$$

Then, the number of consecutive combinations to be analyzed was defined. Several combinations were analyzed sequentially $\left(N_{\text {Comb }}\right)$. The model also considered the possibility of intermediate irrigation days without fertilizer. Furthermore non-fertigated sectors were included in the scenarios in order to analyze their effects on EFT.

\section{Results and discussion}

\subsection{Assessment of the case study}

Fig 2 shows the fertilizer distribution throughout the network during a scheduled irrigation day. Darker pipes represent those sections of the network that the fertilizer has reached. Darker nodes represent multi-outlet hydrants with at least one intake operating at that moment. The first picture shows the network empty of fertilizer. After fertilizer injection, the fertilizer travels along the network system. The fertilizer pump was stopped at 3:30 pm and the non-fertigated intakes were opened at 4:00 pm. All irrigation ends at 6:00 pm. The last picture shows the non-flushed fertilizer in the network.

Table 1 shows the EFT avg and $E F T_{\text {std }}$ values in each of the fertigated sectors. The results for all fertigating intakes are $E F T_{a v g}=86.67 \%$ and $E F T_{S t d}=24.21 \%$. The first operating sector (S1) has a lower $E F T_{a v g}$ and higher $E F T_{S t d}$ than the other sectors because the fertilizer needs a travel time to flow from the injection point to the demand points. The other sectors have the advantage that the fertilizer is already traveling through the network when they start to operate.

Fig 3 shows the unequal distribution of fertilizer in S1 and highlights that some intakes receive no fertilizer even when users are paying for it.

Although all users pay the same for the fertigation they do not receive the same amount.. Moreover differences in fertigation can have repercussions in crop yield, due to scheduled fertilizer doses not being applied to crops and the requirements being not satisfied.

Fig 4 illustrates the EFT of the sector without fertilizer (S6). Note that although the fertilizer pump stops 30 minutes earlier, several intakes receive fertilizer during $100 \%$ of $T_{\text {Irri }}$. These intakes receive fertilizer and their owners do not pay for it. Moreover this can interfere with their own fertigation programs as users may not have taken into account the fertilizer dissolved in the water. Only with a previous irrigation without fertilizer would be guaranteed fertilizer will not achieve these intakes. 


\subsection{Application of GA methodology}

The GA methodology was applied to the case study in two scenarios with 5 sectors each: one scenario grouped the intakes into hydrants ( $\mathrm{Sc} 1)$ and the other did not group the intakes (Sc2). Intakes whose users do not want to use central fertigation were grouped in one sector $\left(\mathrm{S}_{\mathrm{WF}}\right)$ and were not included in the optimization process. Thus scenarios can be compared to the case study where theFTavg $\left(\mathrm{Sc}-\mathrm{S}_{\text {tudyCase }}\right)$ is improvement in performance of these scenarios when compared to the case study. EFT avg does not take into account $\mathrm{S}_{\mathrm{WF} .} W_{\text {PumpJ }}$ is the energy consumption of the pumping unit for each scenario.

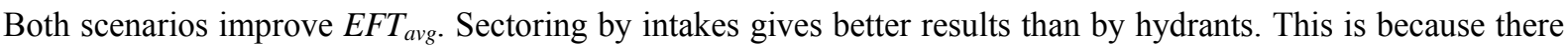
are 331 intakes and 52 hydrants. Thus, the GA grouping by intakes has a higher degree of freedom for optimising the sectors and can search for a better solution than grouping by hydrants where intakes of the same hydrant are constrained to operate at the same time.

The case study has an energy consumption of $729 \mathrm{kWh}$ per irrigation day. Compared to the case study, Sc1 shows a power increase of $8.1 \%$, where as Sc2 shows a power reduction of $10.7 \%$. That is, in Sc2 the resulting EFT values are higher and the energy consumption is lower.

Several scenarios with different numbers of sectors and degree of automation were simulated using the methodology for grouping intakes into sectors to minimize energy consumption instead of the methodology to improve EFT. Table 3 shows the results of two of these scenarios (Sc3 and Sc4) with five sectors plus the sector without fertilizer. In Sc3 the intakes were grouped into hydrants and in Sc4 they were not.

The resulting EFT values for $\mathrm{Sc} 3$ and $\mathrm{Sc} 4$ are similar to the EFT of the case study. However $\mathrm{W}_{\text {PumpD }}$ improves by $23.1 \%$ and $24.4 \%$, respectively. Comparing the results of $\mathrm{Sc} 1$ and $\mathrm{Sc} 3$, the EFT value of Sc1 is $9.69 \%$ higher, which means a higher energy consumption rate (40.7\%). For Sc2 versus Sc4, the EFT of Sc2 is 9.04\% higher, which also indicates higher energy consumption rates $(15.95 \%)$. These GA results show that grouping intakes with the aim of improving EFT does not guarantee pumping groups work efficiently. For this reason combinations of optimal sectors from an energetic point of view were analyzed.

\subsection{Improvement of sector sequence}

Several scenarios were analyzed using an objective function to minimise $E F T_{\text {Avg }}$. The number of consecutive combinations analyzed was one consistent with irrigating using the same timetable on all irrigation days. The analysis (Table 4) was conducted either with or without the non-fertigated sector to evaluate the effects on 
$E F T_{\text {avg. }}$. The with non-fertigated sector treatment involved excluding the fertigation intakes from the analysis. The without non-fertigated sector treatment involved all intakes being fertigated. Similarly, the intakes were either grouped into Hydrants $(\mathrm{H})$ or not grouped (Int).The irrigation sectors used in the analysis were the optimal sectors from an energy perspective. In the last column is showed the sector sequence, that is how sectors are sorted during an irrigation day.

Where only the degree of automation varies, the results for $E F T_{\text {avg }}$ were better at the intake automation level, while the $E F T_{\text {Std }}$ were larger with hydrant automation. When compared with the case study, scenario 7 shows the largest improvement in $E F T_{\text {Avg }}(6.86 \%)$. For those scenarios that include the sector without fertilizer, the best improvement is scenario $12(5.66 \%)$. For the scenarios which have the same number of sectors as the case study (Sc13 and Sc14) the improvements are $2.23 \%$ and $3.37 \%$.

When the same sector operates on the first shift after an irrigation period without fertilizer, the EFT will be reduced. For this reason, if the order of this sector is modified in the next irrigation shift, its EFT would be expected to improve. To evaluate the effect of changing sector order over several irrigation days, new scenarios were analyzed (Table 5). Two sectorings, one with seven irrigation sectors and another with five sectors plus one non-fertigated sector, were analyzed. It was also considered whether irrigations with fertigation (IRFertC) were consecutive (c), non-consecutive (nc) and if there was an intermediate shift without fertigation ( $\left.1 \mathrm{~S}_{\mathrm{wf}}\right)$. The objective function was maximizing the $E F T_{\text {avg. }}$ Fig 5 illustrates the results of the different sector order combinations for scenarios 17 to 21 .

In the seven-sector scenarios ( $\mathrm{Sc} 17, \mathrm{Sc} 19, \mathrm{Sc} 21)$, a higher number of consecutive combinations with fertigation results in lower $E F T_{\text {avg }}$ values and higher $E F T_{S t d}$ values. When there are intermediate irrigation shifts without fertilizer, since the objective function is not $E F T_{S t d}$, it is not necessary to change the selected sector combination at the next irrigation shift with fertilizer because this sector combination maximizes $E F T_{\text {avg }}$ values.

The $E F T_{\text {avg }}$ differences for the scenarios with the same number of combinations are greater as the number of combinations increases (4.46\% between Sc18 and Sc19, 5.83\% between Sc20 and Sc21). In comparison to the case study, the best result is scenario 20 , with three consecutive irrigations and an improvement of $10.5 \%$ for $E F T_{\text {avg }}$ and $16.34 \%$ for $E F T_{\text {Std. }}$.

iError! No se encuentra el origen de la referencia.Fig 6 shows the results of the different sector order combinations for scenarios 22 to 28 . In these six sector-scenarios, the presence of an irrigation sector without fertigation decreases $E F T_{\text {avg }}$ when compared to the same scenario with consecutive fertigation where all sectors are fertigated. This is because there is a period of time when no fertilizer is injected into the network. The 
difference becomes greater when the number of combinations increases (e.g. 3.73\% between Sc23 and Sc25, $5.01 \%$ between Sc26 and Sc28). In the case of three consecutive combinations without $S_{W F}$, the improvement over the case study is $10.4 \%$, where as the presence of $S_{W F}$ reduces this improvement to $5.03 \%$. Similarly, $E F T_{\text {avg }}$ decreases for intermediate irrigations without fertilizer (4.97\% between Sc23 and Sc24, 6.58\% between Sc26 and Sc27). Hence, a shift without fertigation has the same effect as an intermediate irrigation without fertilizer.

\section{Conclusions and future research}

The only rational way of managing central fertigation processes in pressure irrigation networks is by grouping the intakes into sectors that operate on scheduled irrigation shifts. Fertilizer needs a travel time to flow from the injection point to consumption points. Travel time depends on the flow rate and distance to the consumption point. Therefore, it is necessary to know how the fertilizer can be distributed uniformly along the irrigation system. Hydraulic simulation models can be used to analyze fertilizer distribution. These models together with genetic algorithms are valuable tools to improve central fertigation management and design.

Fertilizer management becomes more complex if some users do not make use of central fertigation and there are intermediate irrigation shifts without fertigation. The latter problem can be solved by increasing the number of fertigations and decreasing the concentration of applied fertilizer. The total amount of fertilizer delivered through the network is the same. As a result, the number of intermediate irrigations without fertigation decreases, and the fertilizer does not need more travel time to reach the consumption point; in this way the first irrigation sector is not always affected by this fact, because when it operates fertilizer is already travelling by the network and its EFT increases.

The presence of users that do not fertigate affects fertilizer distribution uniformity. When non-fertigating intakes are operating, it is difficult to ensure that fertilizers do not reach the intakes even if the injection system was stopped long before these intakes are opened. One way to decrease the amount of fertilizer that reaches these intakes is to ensure this sector operates in the first position after an irrigation shift without fertilizer and then assign this sector to the last irrigation shift. However, these schedule changes may not be acceptable to users, In the system design phase the presence of these users should be evaluated and if an acceptable EFT is not achievable then the central fertigation system should be discarded.. If there are users that practice organic farming and share the distribution network, central fertigation should not be applied because it is difficult to guarantee fertilizer does not reach their intakes.

In networks controlled by direct pump injection, an efficient sectoring with a better fertilizer distribution may not result in efficient power consumption. Given the difficulty of quantifying the economic impact of improving EFT, a good performance option is to find the sequence of the optimal energy sectors that improve EFT. Although the results are not as good as those that only search to improve EFT, in this case optimal energy consumption is also improved. The methodology introduced in this study may be applied to other schemes, but 
the results of this study case should not be extrapolated to other schemes due to differences in design and performance.

\section{Acknowledgements}

The authors wish to thank the company TECVASA (Técnicas Valencianas del Agua S.A) for its collaboration in the development of this work and provision of data.

\section{References}

Arviza, J y Balbastre, I. (2002)a. "Redes de Riego a presión. Consideraciones sobre la fertirrigación colectiva". Revista Levante Agrícola $n^{0} 359.1^{\text {o }}$ trimestre. Págs. 70-81.Ediciones y promociones LAV SL. Valencia

Arviza, J y Balbastre, I. (2002)b. "Redes de Riego a presión. Consideraciones sobre la fertirrigación colectiva. Parte II”. Revista Levante Agrícola n 360. $2^{\circ}$ trimestre. Págs. 133-139. Ediciones y promociones LAV SL. Valencia

Arviza J., Martínez, F. y Balbastre I (2002) . Análisis de la distribución de fertilizantes en sistemas colectivos de riego a presión. XX Congreso Nacional de Riegos. Ciudad Real. España

Bracy RP, Parish RL, Rosendale RM (2003) Fertigation uniformity affected by injector type. Horttechnology 13:103-105

Jiménez. M.A. Martínez. F.. Arviza. J.. Manzano J.(2006) Herramientas para el uso racional del agua con el apoyo de un GIS (HuraGIS). XXIV.Congreso nacional de riegos. Lugo (Spain). (Jun 2006)

Jiménez M.A., Martínez F., Arviza J., Manzano J. (2008) Optimización de la sectorización de redes de riego a presión mediante algoritmos genéticos XXVI.Congreso nacional de riegos. Huesca. (Jun 2008)

Jiusheng Li, Yibin Meng, Bei Li (2007) Field evaluation of fertigation uniformity as affected by injector type and manufacturing variability of emitters. Irrigation Science. 25:117-125

Kalyanmoy D (2001). Multi-Objective Optimization using Evolutionary Algorithms. John Willey and Sons. Englland

Goldberg, D.E. (1989). Genetic algorithms in search, optimization and machine learning., Addison-Wesley, Reading, MA. 
Rossman, Lewis A. (2000). Epanet 2, Users Manual. Water Supply and Water Resources Division. National Risk Management Research Laboratory. Cincinnati. USA

Savic D, Walters G. (1997).Genetic Algorithms for least-cost design of Water Distribution Networks. Journal of Water Resources Planning and Management.March . Volume 123, Issue 2, pp. $67-77$ (March/April 1997) 


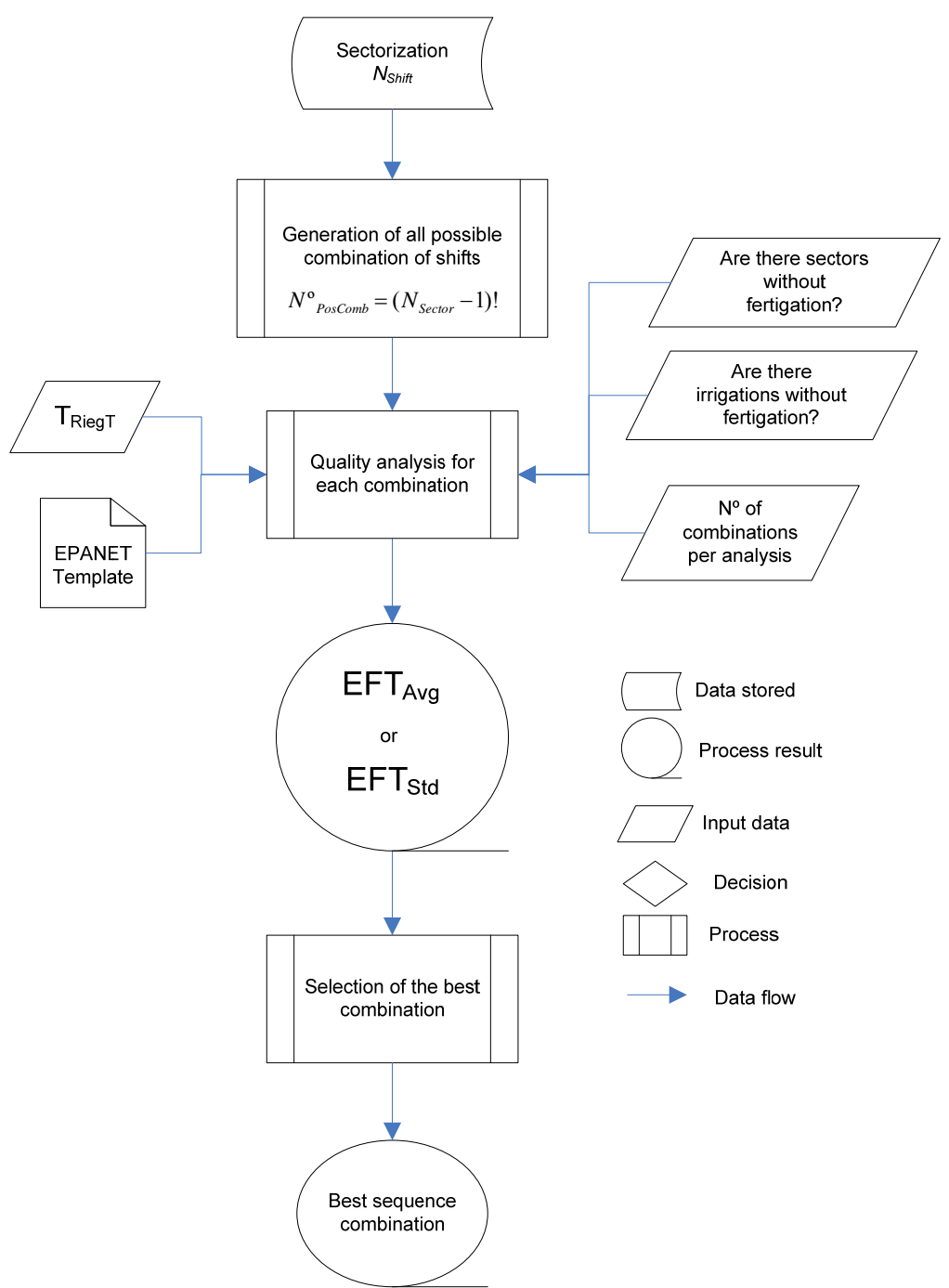

Fig 1 Selection of combination sequences 


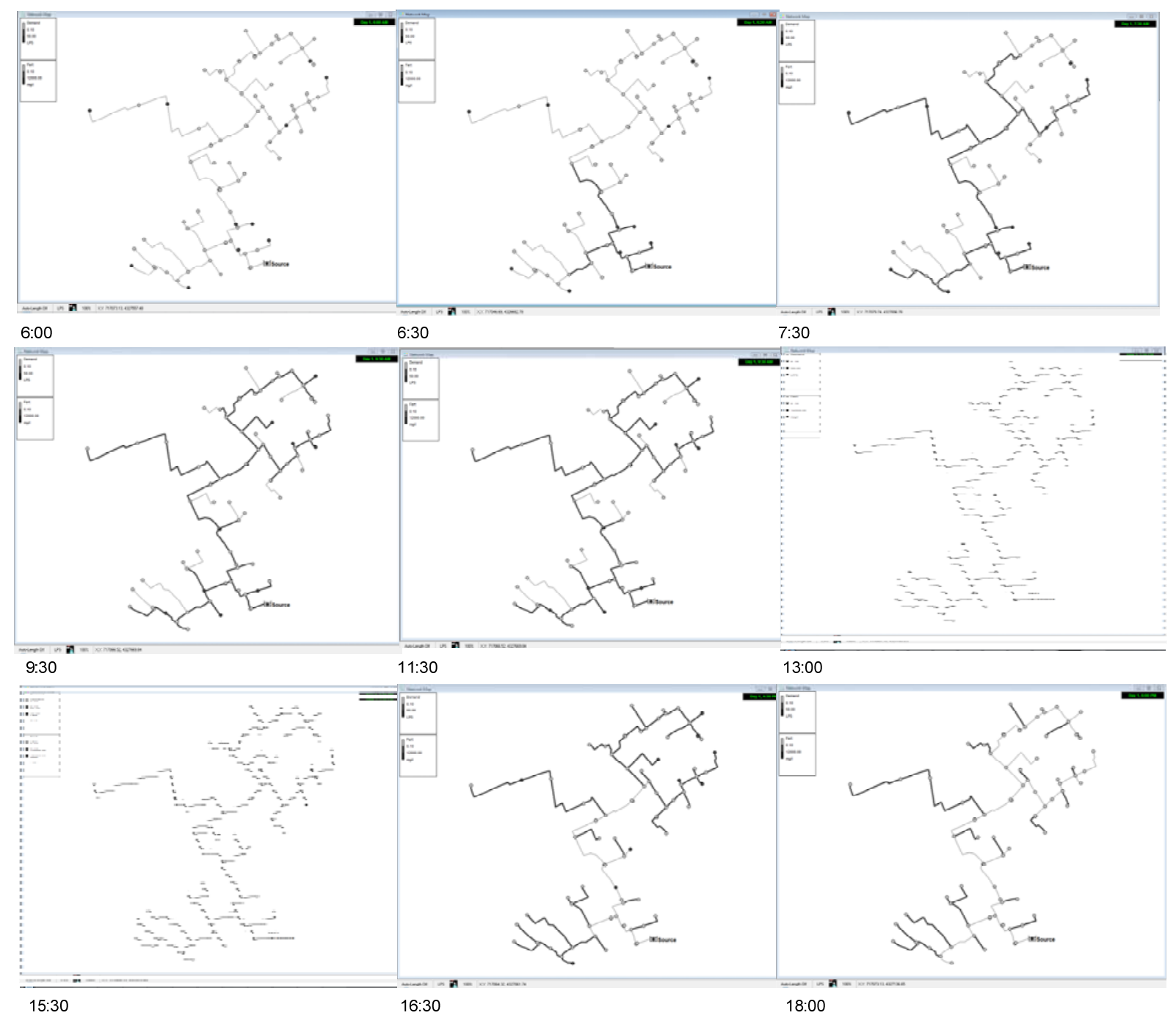

Fig 2 Fertilizer distribution during an irrigation day for the case study 


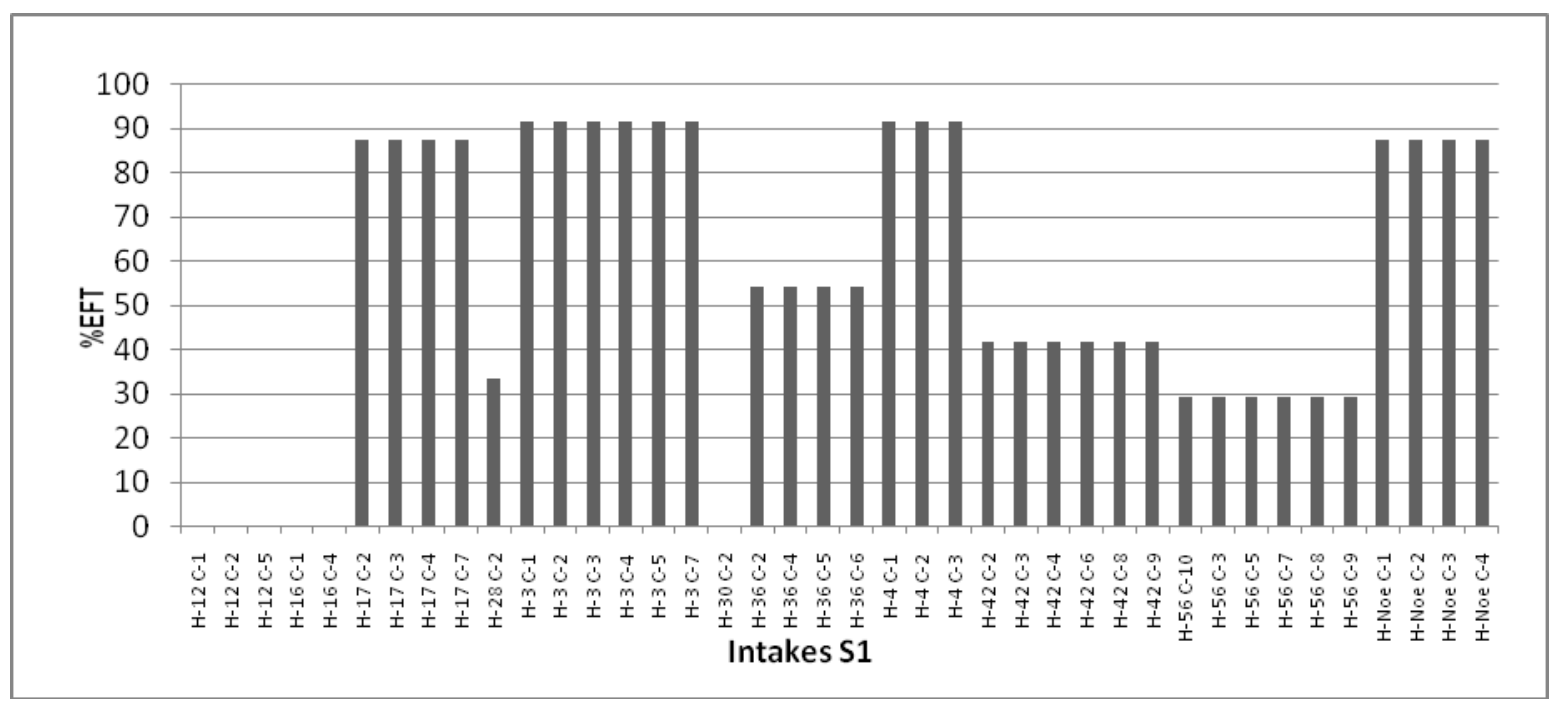

Fig 3 EFT for the first sector (S1) 


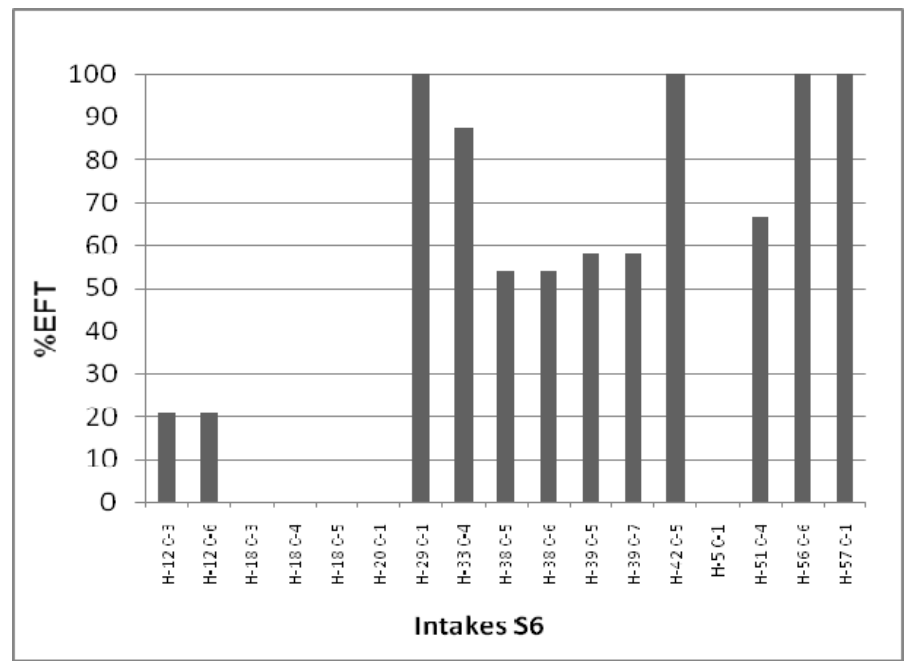

Fig 4 EFT of the sector without fertilizer 


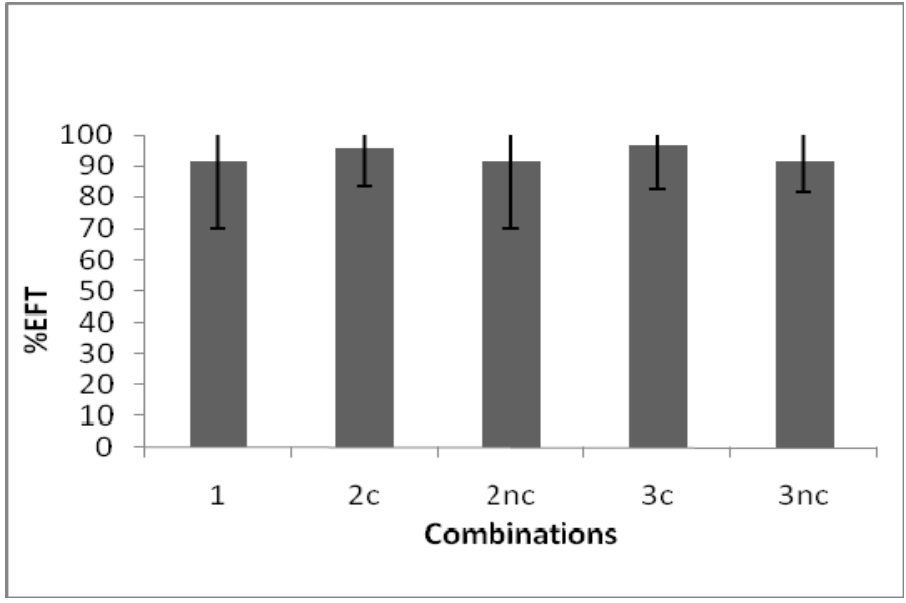

Fig 5 EFT(\%) of sector combinations for scenarios 17 to 21 where irrigations with fertigation were consecutive (c)and non-consecutive (nc) 


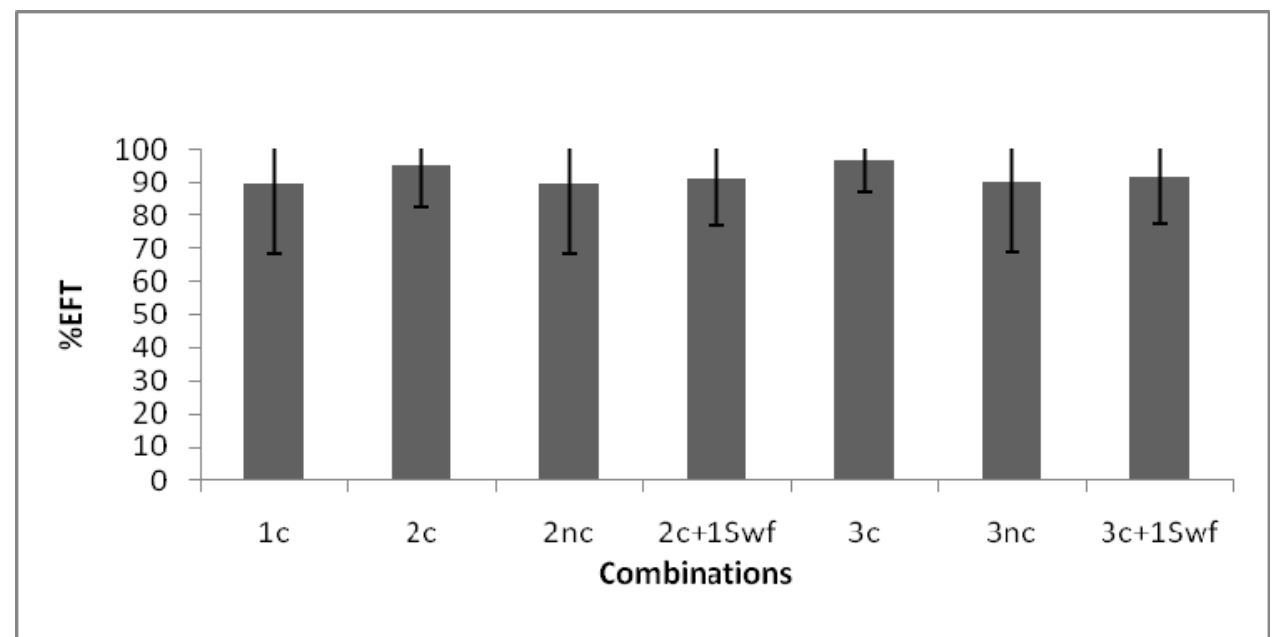

Fig 6 Performance of sector combination for scenario 22 to 28 where irrigations with fertigation (were consecutive (c), non-consecutive (nc) and if there was an intermediate shift without fertigation $\left(1 \mathrm{~S}_{\mathrm{wf}}\right)$ 
Table 1 EFT for each shift

\begin{tabular}{|l|r|r|}
\hline Sector & \multicolumn{1}{|c|}{ EFT $_{\text {avg(\%) }}$} & \multicolumn{1}{|c|}{ EFT $_{\text {Std(\%) }}$} \\
\hline S1 & 55.00 & 33.68 \\
\hline S2 & 96.57 & 14.64 \\
\hline S3 & 96.02 & 3.35 \\
\hline S4 & 92.97 & 20.61 \\
\hline S5 & 91.97 & 27.76 \\
\hline S6 & 48.28 & 40.31 \\
\hline
\end{tabular}


Table 2 Results of applying GA to improve fertilizer distribution

\begin{tabular}{|l|l|l|l|l|}
\hline Sc & $\mathbf{N}_{\text {Sectors }}$ & $E F T_{\text {avg }}(\%)$ & $\begin{array}{l}E F T_{\text {avg }}(\%) \\
(\text { Sc-S }\end{array}$ & $\begin{array}{l}W_{\text {Pump }} \\
(\mathrm{kWh})\end{array}$ \\
\hline Sc1 & $5+1 \mathrm{~S}_{\mathrm{WF}}$ & 94.03 & 7.36 & 788 \\
\hline $\mathrm{Sc} 2$ & $5+1 \mathrm{~S}_{\mathrm{WF}}$ & 97.55 & 10.88 & 639 \\
\hline
\end{tabular}


Table 3 Results of applying GA to decrease energy consumption

\begin{tabular}{|l|l|l|l|}
\hline Sc & N Sectors & $E_{\text {Fivg }}(\%)$ & $W_{\text {PumpD }}(k W h)$ \\
\hline Sc3 & $5+1 \mathrm{~S}_{\mathrm{WF}}$ & 84.34 & 560 \\
\hline Sc4 & $5+1 \mathrm{~S}_{\mathrm{WF}}$ & 88.51 & 551 \\
\hline
\end{tabular}


Table 4 Analysis of the results for one sector combination

\begin{tabular}{|l|l|l|l|l|l|l|}
\hline Esc & N sectors & At & $\begin{array}{l}\text { W PumpJ } \\
(\mathbf{k W h})\end{array}$ & $\begin{array}{l}E F T_{\text {avg }} \\
\mathbf{( \% )}\end{array}$ & $\begin{array}{l}E F T_{\text {Std }} \\
\mathbf{( \% )}\end{array}$ & $\begin{array}{l}\text { Sector } \\
\text { sequence }\end{array}$ \\
\hline Sc5 & 7 & H & 475.8 & 91.34 & 14.65 & 4172563 \\
\hline Sc6 & 7 & Int & 468.99 & 93.53 & 17.13 & 1465237 \\
\hline Sc7 & 6 & H & 503.41 & 92.05 & 14.81 & 561423 \\
\hline Sc8 & 6 & Int & 491.18 & 92.91 & 19.03 & 614352 \\
\hline Sc9 & 5 & H & 559.46 & 90.45 & 15.67 & 34125 \\
\hline Sc10 & 5 & Int & 557.24 & 91.99 & 19.44 & 15423 \\
\hline Sc11 & $6+1 \mathrm{~S}_{\mathrm{WF}}$ & H & 509.83 & 91.91 & 12.05 & 231465 \\
\hline Sc12 & $6+1 \mathrm{~S}_{\mathrm{WF}}$ & Int & 499.59 & 92.33 & 17.13 & 214356 \\
\hline Sc13 & $5+1 \mathrm{~S}_{\mathrm{WF}}$ & H & 560.21 & 88.90 & 18.58 & 15423 \\
\hline Sc14 & $5+1 \mathrm{~S}_{\mathrm{WF}}$ & Int & 551.06 & 90.04 & 21.39 & 51234 \\
\hline Sc15 & $4+1 \mathrm{~S}_{\mathrm{WF}}$ & H & 620.90 & 89.84 & 14.53 & 1423 \\
\hline Sc16 & $4+1 \mathrm{~S}_{\mathrm{WF}}$ & Int & 609.24 & 92.23 & 17.09 & 4321 \\
\hline
\end{tabular}


Table 5 Analysis of several sector combinations

\begin{tabular}{|c|c|c|c|c|c|c|c|}
\hline SC & $\mathbf{N}_{\text {Sectors }}$ & $\begin{array}{c}\mathbf{N} \\
\text { Comb }\end{array}$ & $\overline{\text { At }}$ & IR $_{\text {FertC }}$ & $\begin{array}{c}E F T_{\text {avg }} \\
(\mathbf{\%})\end{array}$ & $\begin{array}{c}E F T_{S t d} \\
(\mathbf{\%})\end{array}$ & Sector sequences \\
\hline Sc17 & 7 & 1 & $\mathrm{H}$ & & 91.34 & 14.65 & 4172563 \\
\hline Sc18 & 7 & 2 & $\mathrm{H}$ & $\mathrm{c}$ & 95.80 & 9.25 & $4136275 \# 3415672$ \\
\hline Sc19 & 7 & 2 & $\mathrm{H}$ & nc & 91.34 & 14.65 & $4172563 \# 4172563$ \\
\hline Sc20 & 7 & 3 & $\mathrm{H}$ & $\mathrm{c}$ & 97.20 & 7.87 & $4173625 \# 31246575 \# 127643$ \\
\hline Sc21 & 7 & 3 & $\mathrm{H}$ & $\mathrm{nc}$ & 91.37 & 14.701 & $4172563 \# 4172563 \# 4172563$ \\
\hline Sc22 & $5+1 \mathrm{~S}_{\mathrm{WF}}$ & 1 & Int & & 90.04 & 21.39 & 51234 \\
\hline Sc23 & $5+1 \mathrm{~S}_{\mathrm{WF}}$ & 2 & Int & $\mathrm{c}$ & 95.01 & 12.267 & $51234 \# 12543$ \\
\hline Sc24 & $5+1 \mathrm{~S}_{\mathrm{WF}}$ & 2 & Int & $\mathrm{nc}$ & 90.04 & 21.39 & $51234 \# 51234$ \\
\hline Sc25 & $5+1 \mathrm{~S}_{\mathrm{WF}}$ & 2 & Int & $\mathrm{c}+1 \mathrm{~S}_{\mathrm{WF}}$ & 91.28 & 14.40 & $21534 \# 24153$ \\
\hline Sc26 & $5+1 \mathrm{~S}_{\mathrm{WF}}$ & 3 & Int & $\mathrm{c}$ & 96.71 & 9.67 & $52341 \# 14235 \# 52134$ \\
\hline Sc27 & $5+1 \mathrm{~S}_{\mathrm{WF}}$ & 3 & Int & $\mathrm{nc}$ & 90.13 & 21.18 & $52134 \# 51234 \# 51234$ \\
\hline Sc28 & $5+1 S_{W F}$ & 3 & Int & $\mathrm{c}+1 \mathrm{~S}_{\mathrm{WF}}$ & 91.70 & 14.34 & $21354 \# 21534 \# 24153$ \\
\hline
\end{tabular}

